"Managing Sustainable Organizations"

$5^{\text {th }}-6^{\text {th }}$ November, 2020, BUCHAREST, ROMANIA

\title{
JAPANESE COMPANY SUCCESS FACTORS - CULTURE AND LEADERSHIP MINDSET FOR ORGANIZATIONAL SUSTAINABILITY IN DIFFICULT ECONOMIC AND SOCIAL CLIMATES
}

\author{
Toru TAKAHASHI ${ }^{a}$, Kurtz LAW ${ }^{b}$, Claudiu CICEA \\ a,b,c Bucharest University of Economic Studies, Romania
}

DOI: $10.24818 / \mathrm{IMC} / 2020 / 02.20$

\begin{abstract}
Studies have shown that Japan has the most significant number of existing companies with histories over 200 years. Additionally, many of the companies with 100-year histories are Small and Medium sized Enterprises (SMEs). This research explores the features of long-lived companies and compares with the studies of Takubo and Goto to examine whether historical-critical success factors may have future implications on global organizational sustainability. This paper explores how these factors support sustainable growth based on the commitment to continuous innovation, and identify core elements of sustainability for organizations to endure market shifts and times of uncertainty.
\end{abstract}

KEYWORDS: longevity, enduring companies, sustainability, transformation, Japan.

\section{INTRODUCTION}

Established by the laws of the Tokugawa government in 1634 and continuing for approximately 200 years, Japan entered into a period of relative isolationism with European countries. Japanese were prohibited from going abroad and foreign vessels were closely watched and reported. Nonetheless, there is evidence of 3,183 businesses that were established between 1603-1868 which are still existing and operating today (Nippon, 2018). With increasing Western intrusion into Japanese waters in the 19th century, culminating in Commodore Perry's threat of war, forced the Japanese to negotiate a treaty with the United States in 1854 (Howell, 2008) effectively ending isolationism with the West. From 1868-1869, a civil war ensued culminating in the establishment of the Meiji government (18681915) bringing European customs and practices to Japan and stimulating a nationwide change in the concept of class-boundaries with a greater emphasis on the social acceptance relating to the significance of money-making (Sumikawa, 1999). Until 1868, the merchant class had been known as the chonin, which was recognized as the lowest class in the social structure. Indeed, the merchant class had been associated with a negative stigma (Horie, 1936). Arguments have been made to suggest that the chonin were the main instigators of industrialization in Japan (Yamamura, 1969). Nonetheless, the Meiji government sought to improve social infrastructure such as railways, shipping and communication (Sumikawa, 1999), as well as investing highly into acquiring Western technology and expertise (Brown, 2005). Since 1868, 28,972 firms had been established representing 88.5\% of companies in Japan with histories of at least 100 years. Later landmark events which highly impacted the Japanese economy and brought both disruption and economic depression relate to the aftermath of World War 2 and the effects of two nuclear bombs. Japan's human loss represented 1.2 million, approximately 4\% of Japan's pre-war population (Kesternich, et al., 2012). In addition, Harrison (1998) suggests that in 1945, Japan suffered from deprivation of imports. More modern circumstances include the subprime loan crisis

\footnotetext{
*Corresponding author. E-mail address: t-takahashi@globis.co.jp
} 
known as the Lehman Shock in Japan and shifts in market demand brought about by technological advancements.

The question therefore exists as to what makes Japanese companies unique that they can survive crises such as economic depression, revolution, nationwide changes in identity and social practices. This article will address these aspects and determine whether these past success factors are still valid in today's period of modernization.

In addition, in determining whether the success factors of Japanese firms in the past are applicable to the present and the future, this article explore whether there are similarities with the success factors of long-lived firms other than Japanese firms.

\section{LITERATURE REVIEW}

There are many factors which can guarantee the success of companies on the market. Among them we can mention general government expenditures or education level of population (Cicea et al., 2019), organizational resources (Kotas, 2015), managerial competencies or organizational culture (Raisiene, 2016).

Regarding the Japanese environment, Takubo (2014) reported that a Japanese construction company founded in 578AD named Kongo-gumi, is the world's oldest company. The 69 companies researched in his study, had more than 300 years lifespan and annual sales of at least five billion Japanese yen. The research focused on three changes that companies face in looking at the secret to longevity: changing times, changing generations, and changing business. For each of these changes, the common phenomena observed in Japanese long-lived companies are concerned with management knowing their limits for continuity in both peacetime and emergency, connecting the values that support sustainable companies, and delivering customer value in line with core capabilities and values. These attributes are not solely the domain of Japanese companies for example, De Geus (1997) wrote that corporations often fail because management focuses too much on producing goods and services than staying alive. Tapies and Fernandez (2010) identified that family unity, innovation and the capacity for sacrifice in Spanish companies had most impact on a company's longevity and Jaramillo, et al., (2018) determined that value variation between business sectors, customers and supplier client relationships have a high impact on sustainability.

Furthermore, Takubo identified three elements necessary for consideration. Firstly, that management must know its own limitations and are subdivided into management style, capital and finance, and governance. Secondly, connecting values are subdivided into the president, employees, successors, and external stakeholders. Thirdly, customer value is subdivided into core capabilities, organizational capabilities, and customer value. Goto (2009) supports Takubo and further identifies four trends in Japanese enduring companies. These relate to the accumulation of management systems as internal factors of the company, long term expansion of the market economy as external factors of management and the existence of a strong will to continue and develop family businesses. Finally, the existence of an ideological factor to persist family businesses is important to understanding fundamental qualities of long-lived companies. In particular, the last point touches on the role played by Baigan Ishida (1685-1744) who introduced the concept of shingaku which legitimized putting customer satisfaction ahead of profit (Bevacqua 2005).

Takubo (2014) also suggests that the three common elements underpinning the management of a Japanese sustainable company are coexistence with the community, making use of rituals and festivals in management, and developing employees through organizational learning. Both Takubo and Goto seem to acknowledge the importance of spiritual pillars and the importance of constantly educating employees to adapt to change. 


\section{RESEARCH OBJECTIVES}

This research examines the 18 Henokiens (2020) case studies written by a variety of professionals and academics on the subject of global companies which have survived for more than 200 years. Considering that the average lifespan of companies on the S\&P 500 is approximately 33 years, it is interesting to consider why and how these other companies have survived for significantly longer (Anthony, et al., 2018). Also, the question arises as to what degree survivability is a factor of success. Where lies corporate responsibility in the long-term, for example to stakeholders or to shareholders? This research study seeks to verify or contribute to the validation of the findings of Takubo and Goto.

\section{RESEARCH METHODOLOGY}

In this study, data analysis was conducted in the following steps: The Henokiens case studies were individually examined and key phrases were collected. The researchers read and comprehended the data and meaningful words, phrases and concepts were logged and coded. Codes were grouped into categories and categories were grouped into themes. Finally, thematic descriptions were developed to explain the companies' success factors relating to their longevity. Themes had several categories such as shown in figure 1.

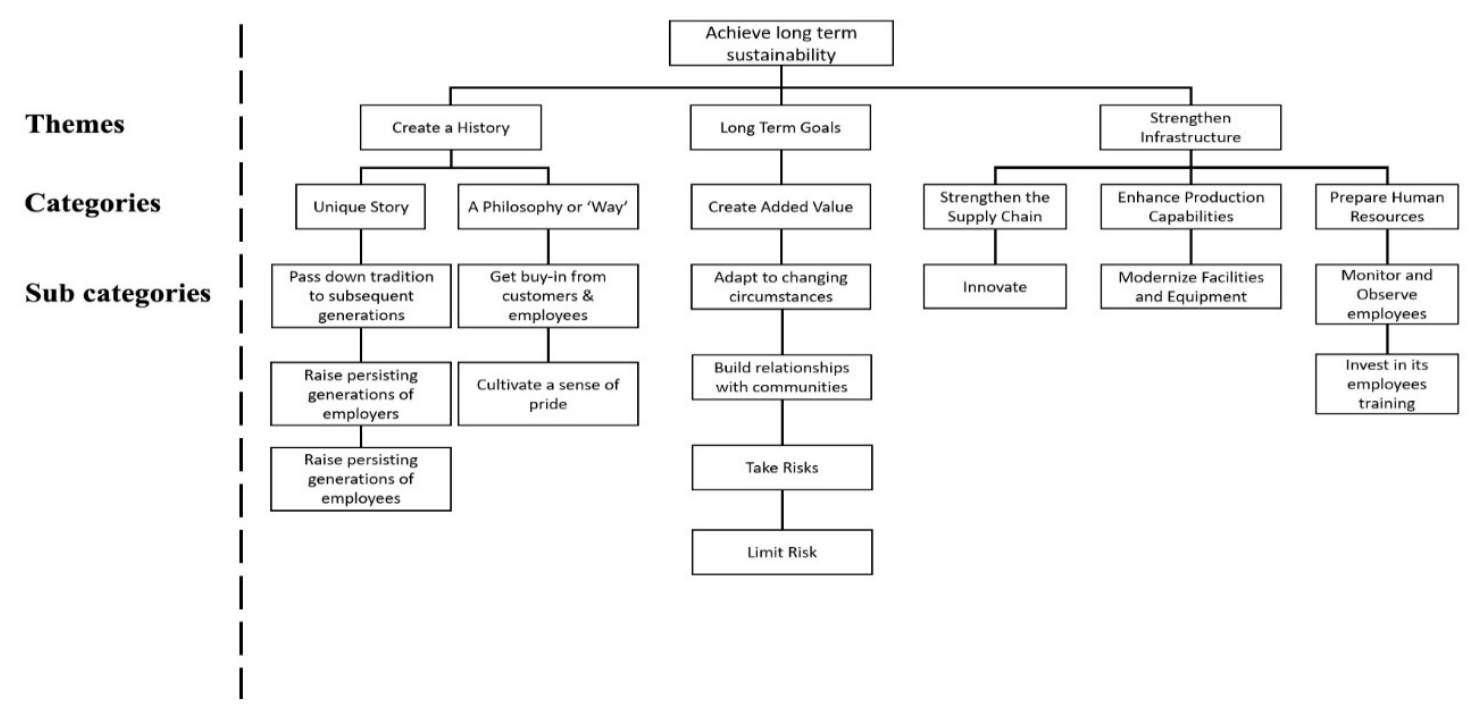

Figure 1. Illustration of the Sub-categories, Categories and Themes Source: Author's own conception

In qualitative research, meanings are derived from words and images not numbers. Since words and images may have multiple meanings, it is necessary to explore and clarify them. This means that the quality of the research depends on the interaction between data collection and data analysis to allow meanings to be explored and clarified (Saunders, Lewis \& Thornhill, 2016). Fielding (2008) suggested that qualitative data analysis involves the comparison between what is said about experiences and behaviors. Subsequently, the raw data codes were organized into conceptual categories and themes emerged from them. Neuman (2007) states that coding is two simultaneous activities consisting of data reduction and analytic data categorization. 
The Henokiens case studies were selected as a comparison with Takubo and Goto due to the similarities of family businesses and 200+ year lifespans. Figure 2 shows the ongoing lifespan of the companies examined through the thematic coding process.

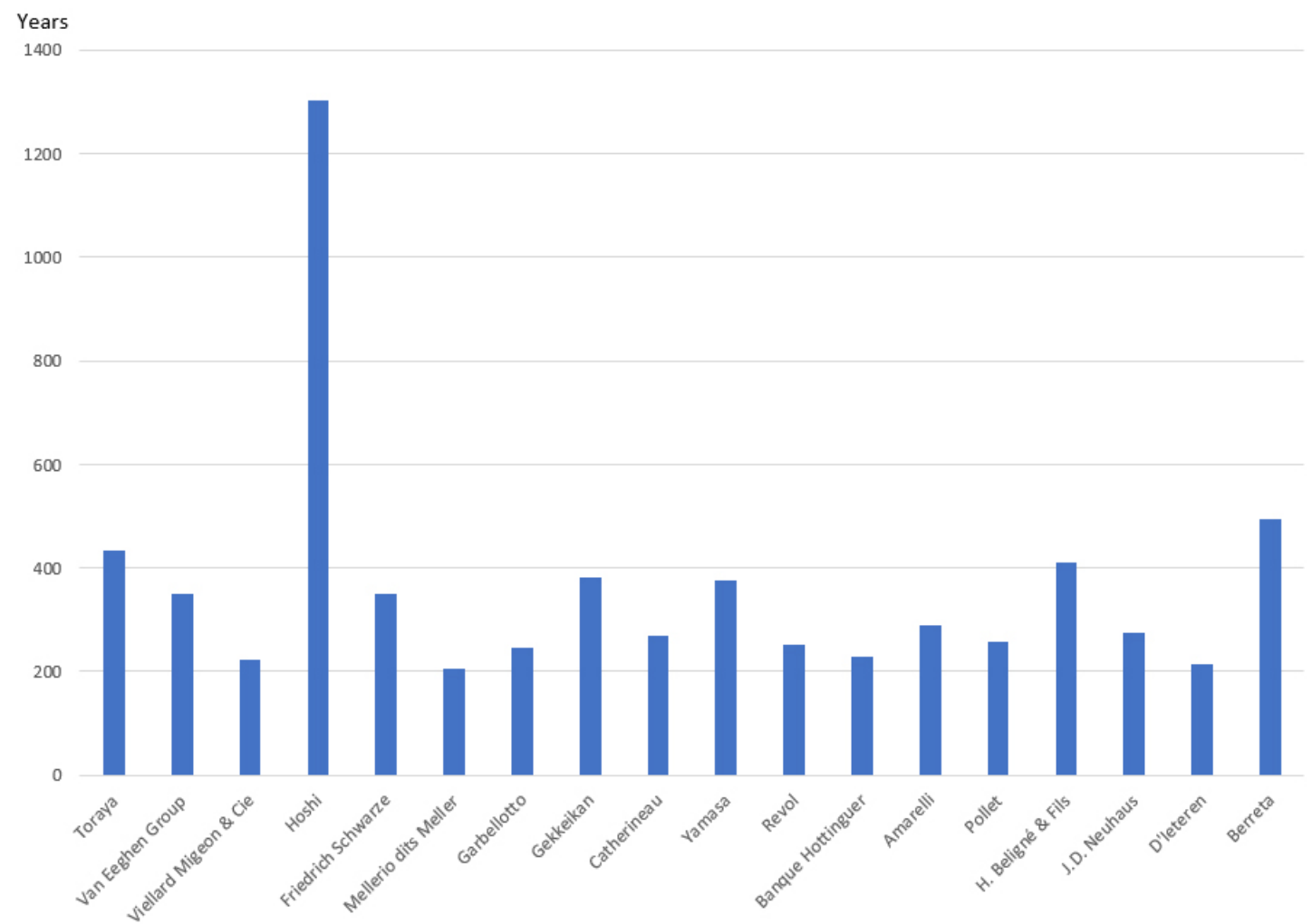

Figure 2. Lifespan of Companies analyzed from the Henokiens Case Studies Source: Author's own conception

\section{FINDINGS \& DISCUSSION}

Bennedsen and Henry (2015) summarized their research of companies in the Henokiens association in Europe, under the theme of building centenary family businesses. They discovered that many family businesses had persisted for more than a century, but in addition started their lives with unique foundations and beginnings unlike typical models found in textbooks. For example, Schwarze GmbH\&Co.KG, an international firm specializing in alcoholic beverages, originally began by producing cereal liquor for local farmers. These villagers drank the spirit before working in the fields and believed that intaking corn each day prevented illness. This was the start of the long-lived company.

Bennedsen and Henry further explain that these businesses succeeded because the families who managed them advocated long-term planning. Additionally, as can be seen in the case of Garbelloto S.p.A, a synergy between production quality, a synthesis with the local environment and centuries of tradition has enabled them to create a key competitive and sustainable advantage.

These can be summarized by the importance to build and establishing close relationships with local key partners. Inherit tradition and culture from one generation of owner to the next. Resonate the founder's values with the companies' employees, customers and other stakeholders.

During the Covid-19 pandemic, while international and interregional migration has been restricted, the sense of micro-tourism is rapidly spreading in Japan. This includes the idea of enjoying microtourism within a region. The question of how well companies are accepted by the communities they 
belong to may be an indicator of longevity in times of crisis. Micro-tourism relates to an overnight or day trip to a local or nearby location within two hours from home. Although the population size of some areas within the micro-tourism area is small, the market size is not necessarily small as there exists a high potential for repeat visitors. Having a mechanism to encourage repeat customers makes the market sustainable and stable (Liu-Thompkins \& Tam, 2013; Asgarpour et al., 2013; Leninkumar, 2017).

Mellerio, a 400-year-old jewellery firm in the heart of Paris, told the story of how Marie-Antoinette came to buy her accessories from the family firm and also gave a fascinating account of how one of her ancestors Jean-Francois Mellerio won over Queen Isabella of Spain with his jewellery collection in 1860, thus becoming a supplier to the royal family (Bennedsen and Henry, 2015). Similarly, Japanese sustainable companies have many anecdotes to tell in their history. Both inside and outside the company, there are stories of the predecessors' successes that have made the company what it is today. These include stories of hardships such as launching a new business, negotiations with difficult customers, and help from business partners. These anecdotes are more than just memories. They are stories of the company's unique way of working, actions based on its values, and the successes and sometimes failures that resulted from those actions, and they are passed on to future generations (Sole \& Wilson, 2002).

According to Takubo's research, there is no significant difference in the basic values expressed in the words of Japanese sustainable companies and good companies in general. What is different, however, is that in Japanese sustainable companies, the decisions made by the president, the behaviour of employees, and the actual actions of employees are based on their values and are "thoroughly implemented". These actions, which have been built up over many years, appear to be something that cannot be imitated by other companies. Recurring crises don't always happen in the same way every time, but where is the nature of the crisis? It is easy to imagine that if you tell the story of how you thought about the crisis, and then practice it thoroughly on a regular basis, you can easily foster crisis response skills. As a result, such companies will continue to increase their ability to survive.

Ideally, for the survival of a company, the shareholders should play a role in watching over the continuous succession of the business, the founding family should play a role in protecting the philosophy and values of the company, and the management should play a role in adapting to the changing times. With these three elements in one place and in the sense that they are easy to control, it seems clear that family businesses have impact on longevity.

However, it cannot be confirmed that a family business will always expect longevity. When a longlived company goes through crisis, shareholders, founders and management must function properly. Management must be able to make an appropriate effort to change the company in the course of the times. Subsequently, communication between parties is important.

\section{CONCLUSION}

Our intention was to verify or contribute to the validation of the findings of Takubo and Goto. Our research also provides an integral discussion regarding Japanese and European companies on the issues of long-term sustainability as we believe that the outcomes could bring general-purpose effects. In particular we found that some of the key commonalities were: generational family-run business, placing customer value above profitability and a sense of sacrifice in the face of unnecessary expansion or as a means of surviving difficult times. In addition, Japanese companies place heavy emphasis on passing down ancient traditions to the next generation while placing value on modern adaptability, as well as success stories were areas of contrast.

Future research will be conducted using interviews for some enduring companies and collecting data and facts to discover how companies feel about whether they can increase sustainability by learning about Japan's long-lived companies. Also, we will further investigate whether the similarities are common on a global scale. Specifically, we want to unravel the common factors which contribute to 
the output of corporate activities, rather than just longer living. Further studies will answer the questions regarding key success factors for long-lived companies which continue to work in an increasingly complex and chaotic macro environment. Alternatively, unravelling what new factors might be needed will have meaningful conclusions for industry and other organizations.

Our research centered on a thematic coding analysis of 18 Henokiens case studies. The outcomes were then compared with the findings of Takubo's and Goto's researches. Potentially, an examination of other case studies outside of the Henokiens group could have yielded different findings. This research focused on a qualitative analysis which relied upon subjective interpretation based on observation and explanation and then formed into concepts, hypotheses and abstractions. Additionally, both Takubo's and Goto's researches were translated from the original Japanese language, and potentially, some interpretation could have been lost during this process.

\section{Acknowledgement}

This study was conducted as part of a doctoral program at the Bucharest University of Economic Studies.

\section{REFERENCES}

Anthony, S.D., Viguerie, P., Schwartz, E.I. \& Landeghem, J.V. (2018). Corporate Longevity Forecast: Creative Destruction is Accelerating. Innosight. Retrieved July 03, 2020, from https://www.innosight.com/wp-content/uploads/2017/11/Innosight-Corporate-Longevity2018.pdf

Asgarpour, R., Hamid, A.B.A., Mousavi, B. \& Jamshidi, M. (2013). A Review on Customer Loyalty as a Main Goal of Customer Relationship Management. Journal of Technology (Social Sciences), 64(3), 109-113.

Bennedsen M. \& Henry, B. (2015). Building Family Businesses that Thrive for Centuries. INSEAD. Wendell International Center for Family Enterprise. Retrieved July 03, 2020, from https://www.henokiens.com/userfiles/file/Editorial_Content_FB_Day_5_Sept_2015_002.pdf

Bevacqua, R. (2005). The Way of the Merchant. Corporate Social Responsibility in Japan. The Economist. May 2005. Retrieved July 10, 2020, from http://graphics.eiu.com/files/ad_pdfs/CSR_JP_English.pdf

Brown, A.D. (2005). Meiji Japan: A Unique Technological Experience? Student Economic Review. Vol 19. 2005. Accessed Feb/20/2020. Retrieved July 10, 2020, from https://www.tcd.ie/ Economics/assets/pdf/SER/2005/Alexander_David_Brown.pdf

Cicea, C., Popa I., Marinescu C., Stefan C.S. (2019). Determinants of SMEs' performance: evidence from European countries, Economic Research-Ekonomska Istrazivanja, 32(1), 1602-1620.

De Geus, A. (1997). The Living Company. Harvard Business Review. Retrieved July 10, 2020, from https://hbr.org/1997/03/the-living-company

Fielding, J. (2008) Coding and Managing Data, N. Gilbert (ed) Researching Social Life. (3rd ed). Sage: London. Chapter 17, 323-352

Goto, T (2009). Three Generations of Companies that Will Not Go Out of Business for 100 Years. The President Press, Japan. $1^{\text {st }}$ edition.

Harrison, M. (1998). The Economics of World War II; An Overview. Cambridge University Press. $1-42$.

Henokiens. (2020). Case Studies and Reports. The Henokiens International Association of Bicentenary Family Companies. Retrieved July 10, 2020, from https://www.henokiens.com/content.php?id=9\&lg=en 
Howell, D.L. (2008). Oxford Encyclopedia of the Modern World. Edited by Peter N Stearns. Oxford University Press. Retrieved July 20, 2020, from https://international.uiowa.edu/sites/ international.uiowa.edu/files/file_uploads/japan_in_tokugawa_period_and_modernity.pdf

Horie, Y. (1936). An Outline of the Rise of Modern Capitalism in Japan. Kyoto University Research Information Repository. Retrieved July 20, 2020, from https://repository.kulib.kyotou.ac.jp/dspace/bitstream/2433/125262/1/ecb0111_099.pdf

Jaramillo, C.H.H., Arimany-Serrat, N., Vidal, D.M. and Ferras-Hernandez, X. (2018). Sustainability values for business: A perspective of value alignment in a supplier-client relationship for case aqualogy. OmniaScience. Retrieved July 10, 2020, from https://www. researchgate.net/publication/323234339_Sustainability_values_for_business_A_perspective_of _value_alignment_in_a_supplier-client_relationship_for_case_Aqualogy

Kesternich, I., Siflinger, B., Smith, J.P., and Winter, J.K. (2012). The Effects of World War II on Economic and Health Outcomes Across Europe. Discussion Paper No. 6296. January 2012. Institute for the Study of Labor (IZA). Retrieved July 20, 2020, from http://ftp.iza.org/dp6296.pdf

Kotas, M. (2015). Key success factors for social services organizations in Poland, ManagementPoland Journal, 19(2), 122-135.

Leninkumar, V. (2017). The Relationship between Customer Satisfaction and Customer Trust on Customer Loyalty. International Journal of Academic Research in Business and Social Sciences, 7(4), 450-465.

Liu-Thompkins, Y. and Tam, L. (2013) Not all repeat customers are the same: Designing effective cross-selling promotion on the basis of attitudinal loyalty and habit. Journal of Marketing, 77(5), 21-36.

Nippon. (Aug 13, 2018). Some of Japan's Longstanding Companies Have Been in Business for Centuries. Nippon.com. Retrieved July 20, 2020, from https://www.nippon.com/en/ features/h00259/some-of-japan\%E2\%80\%99s-longstanding-companies-have-been-in-businessfor-centuries.html

Raisiene A.G. (2016). Performance Success Factors in Hybrid Organizations, Proceedings of 9th Annual Conference of the EuroMed-Academy-of-Business, in volume INNOVATION, ENTREPRENEURSHIP AND DIGITAL ECOSYSTEMS, 1531-1538

Sumikawa, S. (1999). The Meiji Restoration: Roots of Modern Japan. Retrieved July 20, 2020, from https://www.lehigh.edu/ rfw1/courses/1999/spring/ir163/Papers/pdf/shs3.pdf

Saunders, M., Lewis, P. \& Thornhill, A. (2016) Research Methods for Business Students. (7th ed). Pearson: Harlow, England.

Sole, D. and Wilson, D.G. (2002). Storytelling in Organizations: The power and traps of using stories to share knowledge in organizations. Learning Innovations Laboratory. Harvard. Retrieved July 25, 2020, from https://www.researchgate.net/publication/242189756_Storytelling in_Organizations_The_power_and_traps_of_using_stories_to_share_knowledge_in_organizati ons

Takubo, Y (2014). Why do 300-year-old long-lived companies continue to prosper. Toyo-KeizaiPress, Japan. $1^{\text {st }}$ edition.

Tapies, J. \& Fernandez, M. (2010). Values and Longevity in Family Business: Evidence from a CrossCultural Analysis. IESE Business School. Working Paper. Retrieved July 25, 2020, from https://media.iese.edu/research/pdfs/DI-0866-E.pdf

Yamamura, K. (1969). The Role of the Merchant Class as Entrepreneurs and Capitalists in Meiji Japan. Retrieved July 25, 2020, from https://www.jstor.org/stable/pdf/20731132.pdf 